\title{
A KNOWLEDGE-AS-A-SERVICE SUPPORT FRAMEWORK FOR AMBIENT LEARNING IN KENYA
}

\author{
Lucy Waruguru Mburu, Richard Karanja and Simon M. Nyaga \\ KCA University \\ P.O. Box 56808 - 00200 Nairobi Kenya
}

\begin{abstract}
Knowledge as a Service (KaaS) is a relatively new model, albeit one that is rapidly gaining popularity within cloud computing environments. Over the recent years, learners have experienced a constant need to access on demand knowledge that is fully aligned with the paradigm of cloud computing. This need stems from the knowledge that users will be able to access applications and the information therein on demand, without the restrictions that are usually imposed by time and space. The KaaS model terms knowledge as the understanding of information based on its relevance to a specific context and problem area, thus forming a valuable resource for the human decision-making process. As motivated by the global sustainable development goal of ensuring inclusive and equitable quality education to promote learning opportunities for all, this research has developed a framework that is hinged on KaaS and utilizes knowledge from ambient learning systems. The main aim is to provide a platform for disseminating and exploiting the available knowledge to aid the learning process and, thus, to improve the quality of education on the ambient learning system. The research further explores how collaborative effort can be used to form a knowledge network that allows access to heterogeneous sources of knowledge. The research outcomes will benefit knowledge consumers such as the developers of ambient learning systems.
\end{abstract}

\section{KEYWORDS}

Actionable Knowledge, Ambient Learning, Cloud Computing, Decision Trees, KaaS

\section{INTRODUCTION}

Knowledge as a Service (KaaS) has emerged as a popular paradigm for knowledge acquisition though the cloud. According to de Sousa et al. (2016), conventional knowledge management practices are limited in the information age where we are experiencing exponentially growing data, heavy reliance on digital tools and a general shift towards open data and big data. The rigidity of the traditional stand-alone platforms of the client-server architecture renders such platforms incapable of staying at par with information requirements. An effective and efficient solution to this limitation has been cloud computing (Armbrust et al., 2012, Grover et al., 2018). Cloud based information management has changed the landscape of operation by leveraging cloud-operand resources and enabling integration of increasing information value and support for critical processes (Kathuria et al., 2018). Cloud computing is a distributed computing technology comprising three layers:

1) the Software as a Service (SaaS) layer that avails the high-level interaction platform and top-level functionality. This is the layer that a user of the learning platform interacts with directly.

2) the Platform as a Service (PaaS) layer that is responsible for processing of all relevant applications

3) the infrastructure as a Service (IaaS) layer that deals with low-level services such as database administration $(\mathrm{Xu}, 2012)$.

It is into this three-layer configuration that KaaS emerges, in this case to provide a platform for retrieving knowledge that can be leveraged from anywhere, anything and anyone within the distributed computing environment. KaaS has been viewed as a framework of lessons learned, best practices, proven workflows and case studies which allow knowledge to diffuse in an open cloud platform (Ssekakubo et al., 2013). The challenge for researchers now is to integrate KaaS models with technology-enhanced approaches such as ambient learning. 
Ambient learning is a highly innovative integrated knowledge and learning management system which merges the e-learning provision with context-based knowledge management (Al-Busaidi, 2013). The approach of this research is to harness knowledge through information and communication technology (ICT) to realize knowledge gaps in the realization of quality education, in line with the sustainable development goals (SDGs, General Assembly, 2015).

\subsection{Background}

With the SDGs, global development has entered a new stage with clearer focus on current challenges and key means to counter them. This has invariably placed knowledge at the center of how development can be achieved. The SDG goal four focuses on the acquisition of foundational and higher order skills at all stages of education and development with greater and more equitable access to quality education. To date, this goal has not been fully realized in Kenya. The Kenya National Adult Literacy Survey revealed that only $61.5 \%$ of the adult and out-of-school youth above 15 years have attained minimum literacy level leaving $38.5 \%$ (7.8 million) adults illiterate (UNESCO, 2015). A majority of these are individuals from less fortunate backgrounds who have been left out of a chance to attain quality education either due to lack of resources or reading material. With the prevalence of mobile phones where Kenya has a national coverage of about $77 \%$ of the population, the mobile industry covers over 31 million people and is therefore the ideal platform that can be leveraged to bridge this gap to help enhance accessibility of learning materials (Kaliisa and Picard, 2017). A recent survey of 3500 mobile phone users across Africa revealed five major markets; South Africa, Nigeria, Kenya, Ghana and Uganda (IT News Africa, 2015). Kenya recorded a 34\% rate of internet browsing and 19\% rate of downloading software from the app stores. This rate has since gone higher in the subsequent years. The growing adoption of mobile technologies accompanied by ubiquitous connectivity, and the ever-increasing pervasiveness of information technology are changing the conditions for lifelong learning.

\subsection{Problem Statement}

Data is growing exponentially, such that $90 \%$ of the world's stored data has been created in the last two years alone and a major facilitator for KaaS is the huge proliferation of information which includes documents, data, government records, multimedia and tacit knowledge such as blogs that are available in digital format. The implication of this is that the potential for the availability of knowledge for development is huge with the only questions being who owns this knowledge, and how is shared. The idea therefore is to look at the vast data and see how a conceptual framework can be used to focus on inclusive and equitable education while leveraging ambient learning to help improve the livelihoods of the general population.

Despite the available infrastructure to support automated learning and content dissemination, initial observation indicates that little or no research has been conducted to evaluate the effectiveness and drivers of ambient learning. As a result, there are few theoretical models to describe how knowledge regarding education quality can be extracted from ambient learning systems.

\section{THE AMBIENT LEARNING - RELEVANCE AND ARCHITECTURE}

The SDG goal 4 aims to ensure that all people have access to quality education and lifelong learning opportunities. Ambient learning is viewed as the next generation of technology enhanced learning in mobile learning seeks to enable anytime, anywhere and anyhow access to customized and high-quality E-learning material (Mwendia et al., 2014). The technique focuses on the mobility of the learner, the design of learning spaces, lifelong learning and informal learning and describes a world in which technology is both implicit and anticipatory (Parsons, 2014). Ambient learning is thus an example of technology enhanced learning approaches that aims at enhancing access to quality education (Mwendia et al., 2014, 2016). Mobile phones are the most preferred choice for ambient learning because they are mostly available at almost every place and people move around with them most of the time. Globally, Africa, Latin America and Asia experience the largest usage of mobile learning. According to Ambient Insight (2013), 11 African countries had a predicted rate of 30\% adoption for ambient learning as shown in Figure. 1. 


\subsection{The Ambient Learning Architecture}

Two of the most common KaaS models include the Actionable Knowledge as a Service (AKaaS) Model (Depeige \&Doyecourt, 2015) and the Collaborative Knowledge as a Service (CKaaS) model (Krolinger et al., 2015) as discussed below.

\subsubsection{Actionable Knowledge as a Service}

AKaaS is a knowledge management system deployed in the cloud computing environments that seeks to enable available knowledge assets to be gathered and customized according to the knowledge consumer's context and needs. This brings about an evolution from traditional KM that is oriented towards a global knowledge delivery to a model that emphasizes a personalized knowledge acquisition by users. This model can be applied in an ambient learning system like OMAL which at the moment does not give this actionable knowledge aspect on data gathered and analyzed from users.

\subsubsection{Collaborative Knowledge as a Service}

The CKaaS model integrates disparate cloud knowledge through collaboration among distributed KaaS entities with the goal of satisfying consumer knowledge needs (Krolinger et al., 2015).

This research borrows knowledge from the two models above to construct a cloud-based knowledge sharing system that incorporates resources from learning objects, open educational resources and mobile education. Learning analytics which correlate to patterns of student activity with learning outcomes will be derived to support students to reach their potential and the delivery of personalized learning.

\section{METHODOLOGY}

\subsection{Research Design}

The research design applied content analysis method and the creative process for service development. Content analysis includes both observation and document analysis to provide objective, systematic and quantitative description of the given content of communication. This is by asking questions to help describe characteristics of content and make inferences on the causes of the content through questions like what, why, who, and with what effect, thus comprehensively making valid and replicable inferences from data to its context (Prasad, 2004).

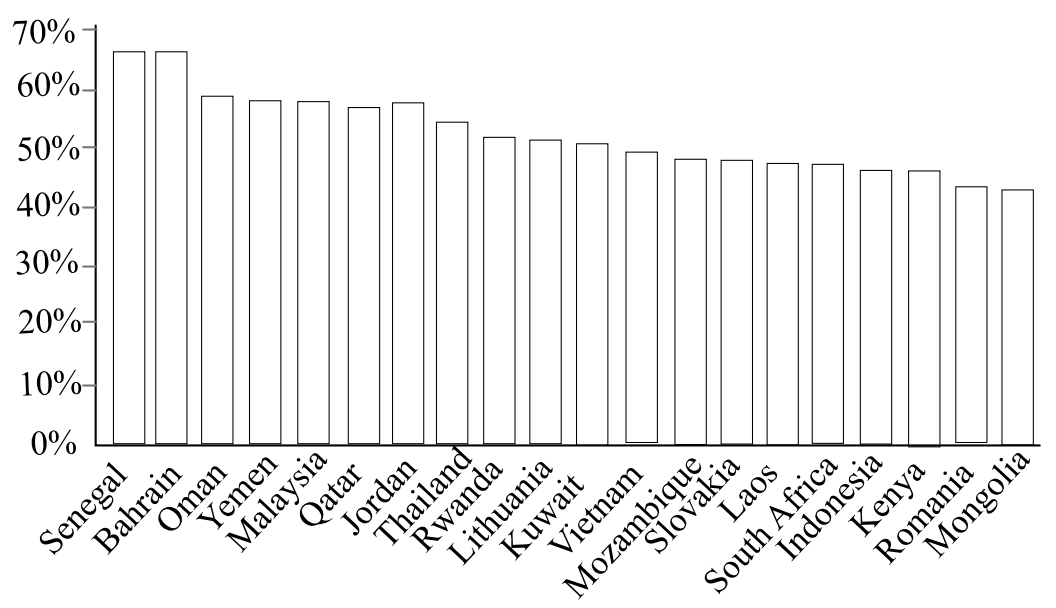

Figure 1. Projected Statistics of mobile learning per country (adopted from Ambient Insight, 2013) 


\subsection{Knowledge Base}

The knowledge base was constructed using the OMAL ambient learning system that is piloted at KCA university, a higher learning institution in Kenya, East Africa. Usage statistics totaling 602 instances were recorded for four of the courses taught at the University, namely Java programming (314 instances), artificial intelligence (112 instances), research skills (42 instances) and management mathematics (134 instances) over a period of three months.

Data from an ambient learning system was used to capture knowledge through a knowledge discovery process known as Knowledge Discovery from Data. This involved combining an abstract model with an ambient learning system and extracting the knowledge through iterative processes consistent with Mwendia (2018). This research however extends Mwendia's approach by substituting the data warehousing approach that uses extract-transform-load (ETL) tools with a virtual data integration approach. This is a modern approach that avails current data on demand and avoids the need to constantly clean and update extracted data (Asano et al., 2018). Knowledge extraction applied the process shown in Figure 2.

\subsection{Analysis Strategy}

Data sets from the OMAL system were analyzed to discover new knowledge in the set of steps shown in Figure 3. Initial analysis of the extracted variables used descriptive statistics such as the measures of central tendency (mean, min, max, standard deviation) as well as the Pearson Chi square $\left(X^{2}\right)$ and Cramer's V tests. The Pearson $X^{2}$ is a significance-based distribution free statistic for measuring group differences among qualitative variables (McHugh, 2013).

Cramer's V test was further used to test the significance levels of the Pearson $X^{2}$ values. Variables that were determined to be significant were further measured using decision tree analysis. Decision tree learning helped to extract significant relationships that will help to strengthen the actionable knowledge for advising the improvement of the ambient learning system through customization and provision of suitable content on the cloud.

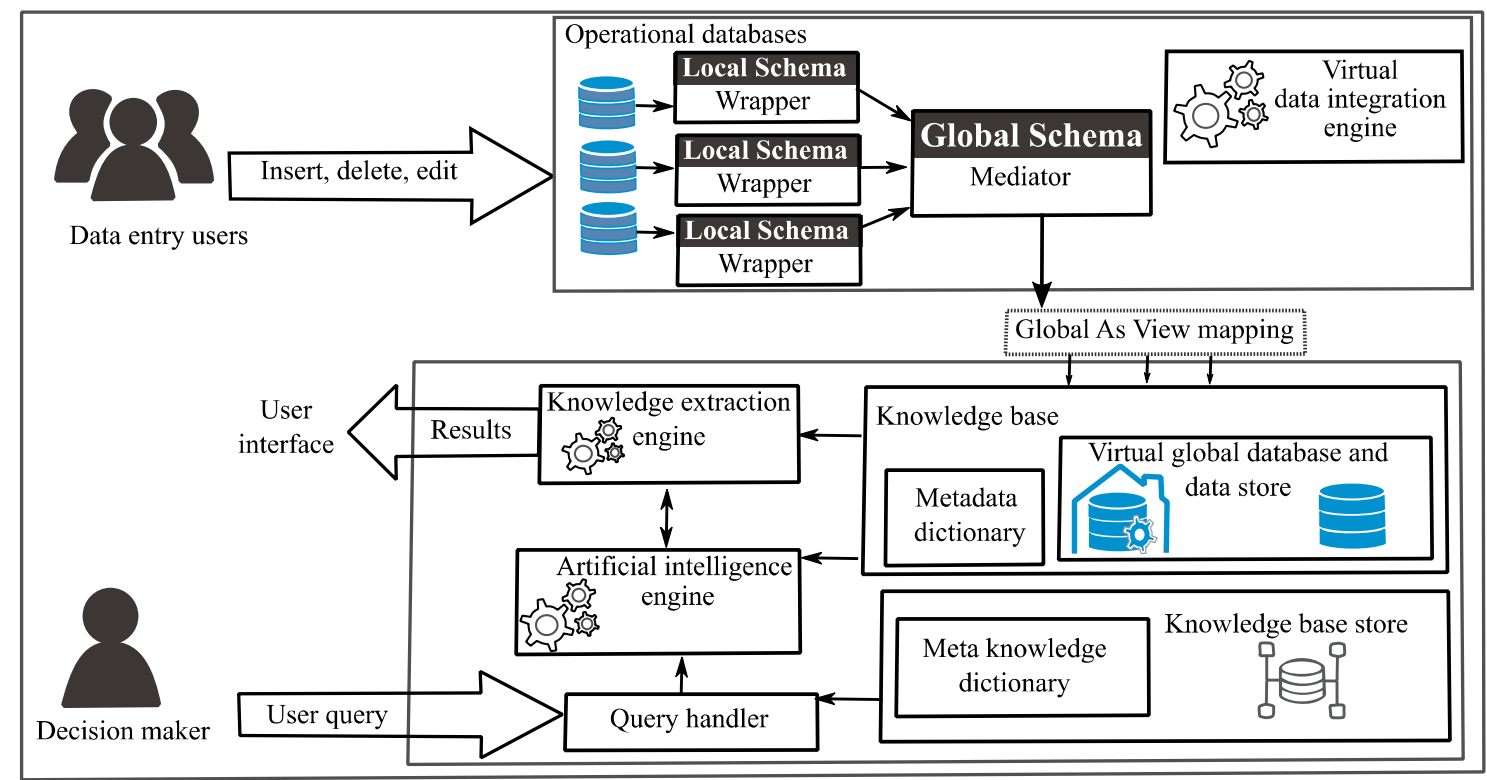

Figure 2. Knowledge extraction process using an ambient learning system 


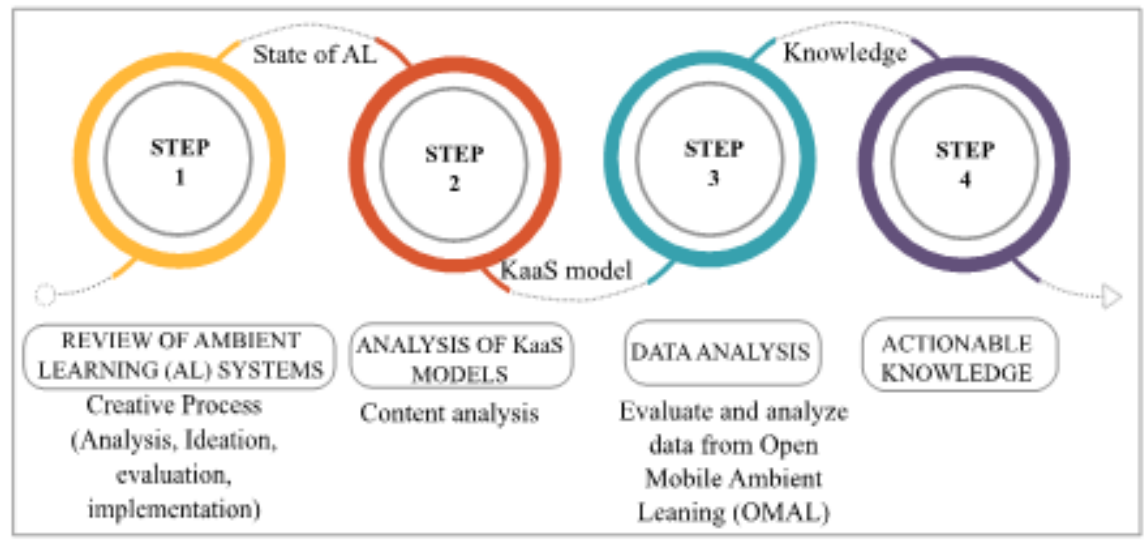

Figure 3. Steps for achieving actionable knowledge from an ambient service

\section{RESULTS}

This section provides results from the statistical analysis and interpretation of the data. In addition to descriptive analysis, we also provide results decision trees modeling with the sampled data.

\subsection{Descriptive Analysis of Influential Learning Factors}

After reviewing two of the common ambient learning (AL) models described above, a model combining the strengths of the two was used to extract knowledge from a developed AL system. Various factors were considered such as the course accessed, the mode of access (e.g. via Google Docs, YouTube, etc.), the stage of learning, day-of-week and time-of-day of access and the reason for accessing (e.g. to read text, watch video, collaborate, etc.)

As shown in Figure 4, Java programming was the course recording the highest usage statistics per week, especially through YouTube. Artificial intelligence had similarly high YouTube access. While Mathematics generally has low access, most of this access was though YouTube. Facebook seemed to be the least preferable access mechanism for ambient learners.

The course Artificial intelligence had the highest level of consistency between expected values and observed values as measured by the Pearson Chi-square statistic. Table 1 shows the summary of significant Chi-square outcomes for access to the Artificial Intelligence course on the ambient learning system. Generally, watching video had the highest frequency of usage, consistent with the descriptive analysis shown in Figure 4 above. Learners also recorded consistent results for reading text and accessing examples from the ambient learning service.

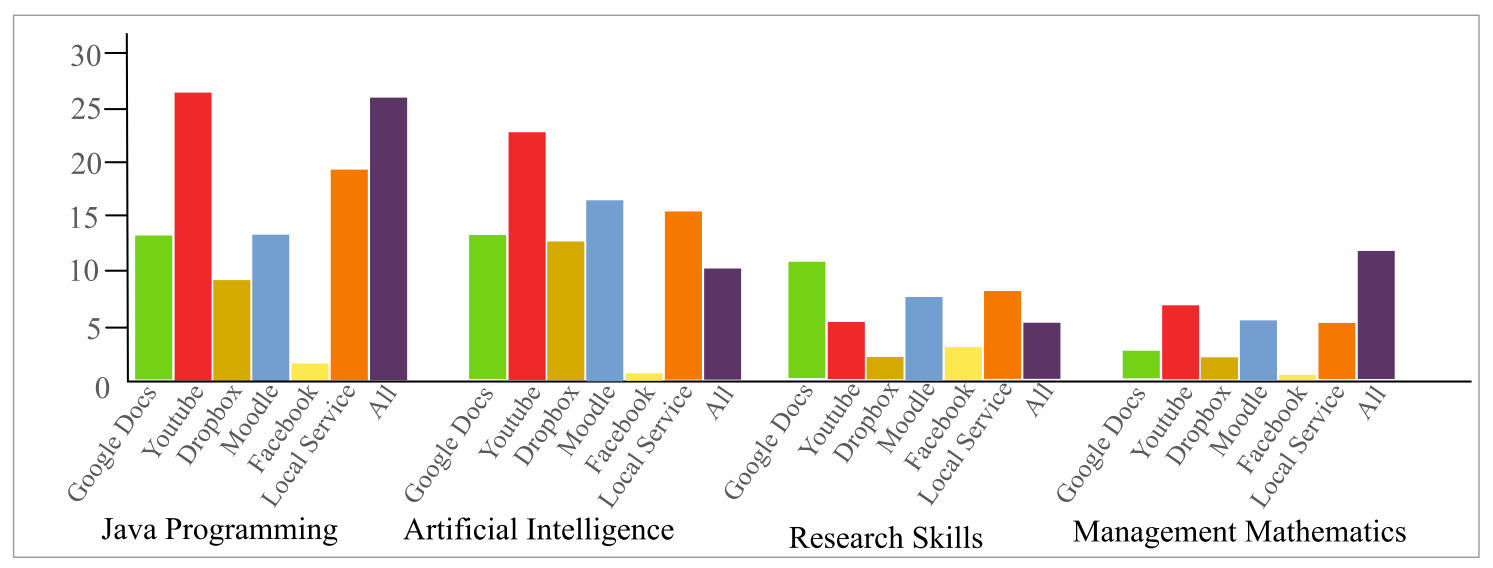

Figure 4. Steps for achieving actionable knowledge from an ambient service 
Table 1. Summary of significant Chi-square outcomes for access to the Artificial Intelligence course

\begin{tabular}{lcccccc}
\hline $\begin{array}{l}\text { Rows: Usage Frequency } \\
\text { Columns: Artificial Intelligence }\end{array}$ & RT & WV & AF & Co & AE & $\begin{array}{c}\text { Row } \\
\text { Margin }\end{array}$ \\
\hline Weekly or less than weekly -- \% of access & 23.5 & 25.3 & 13.2 & 14.1 & 23.9 & 100 \\
Usage frequency (\%) & 42.4 & 61.2 & 60.8 & 51.8 & 53.2 & 74.1 \\
Pearson $X^{2}$ (\%) & 19.8 & 21.7 & 11.6 & 9.9 & 11.1 & 74.1 \\
Cramer's V statistic & 0.001 & 0.000 & 0.005 & 0.001 & 0.000 & \\
Expected Frequency & 25.2 & 23.5 & 9.7 & 11.4 & 13.2 & 83 \\
& & & & & & \\
More than weekly -- \% of access & 23.9 & 34.6 & 11.7 & 11.4 & 18.4 & 100 \\
Usage frequency (\%) & 11.5 & 6.8 & 13.1 & -- & 6.4 & 25.9 \\
Pearson $X^{2}$ (\%) & 9.7 & 6.2 & 2.3 & 1.8 & 5.9 & 25.9 \\
Cramer's V statistic & 0.001 & 0.001 & 0.000 & 0.012 & 0.005 & \\
Expected Frequency & 10.5 & 7.8 & 2.1 & 5.5 & 3.1 & 29 \\
& & & & & & \\
Column Margin -- \% of access & 23.2 & 31.4 & 12.9 & 12.6 & 19.9 & 100 \\
Usage frequency (\%) & 100 & 100 & 100 & 100 & 100 & 100 \\
Pearson $X^{2}$ (\%) & 29.5 & 27.9 & 13.9 & 11.7 & 17 & 100 \\
Cramer's V statistic & 0.000 & 0.000 & 0.002 & 0.005 & 0.002 & \\
Expected Frequency & 32 & 24 & 17 & 18 & 21 & 112 \\
\hline
\end{tabular}

$\mathrm{RT}=$ Read Text, WV= Watch Video, $\mathrm{AF}=$ Access Feedback, $\mathrm{Co}=$ Collaborate, $\mathrm{AE}=$ Access Example

\subsection{Classification Results}

Using a dataset from the Open Mobile Ambient Learning (OMAL) database that was reserved for validation, decision tree analysis was done with 10-fold cross validation resulting in predictions of usage frequencies for ambient learning across different variables. The most important variable was access frequency, and it was discovered that the course highly determines this frequency, with machine-based learning modules such as artificial intelligence being commonly accessed especially during the day and by student in the later learning stage. Mode of accessing AL content was also influential particularly for purposes other than to access feedback and examples.

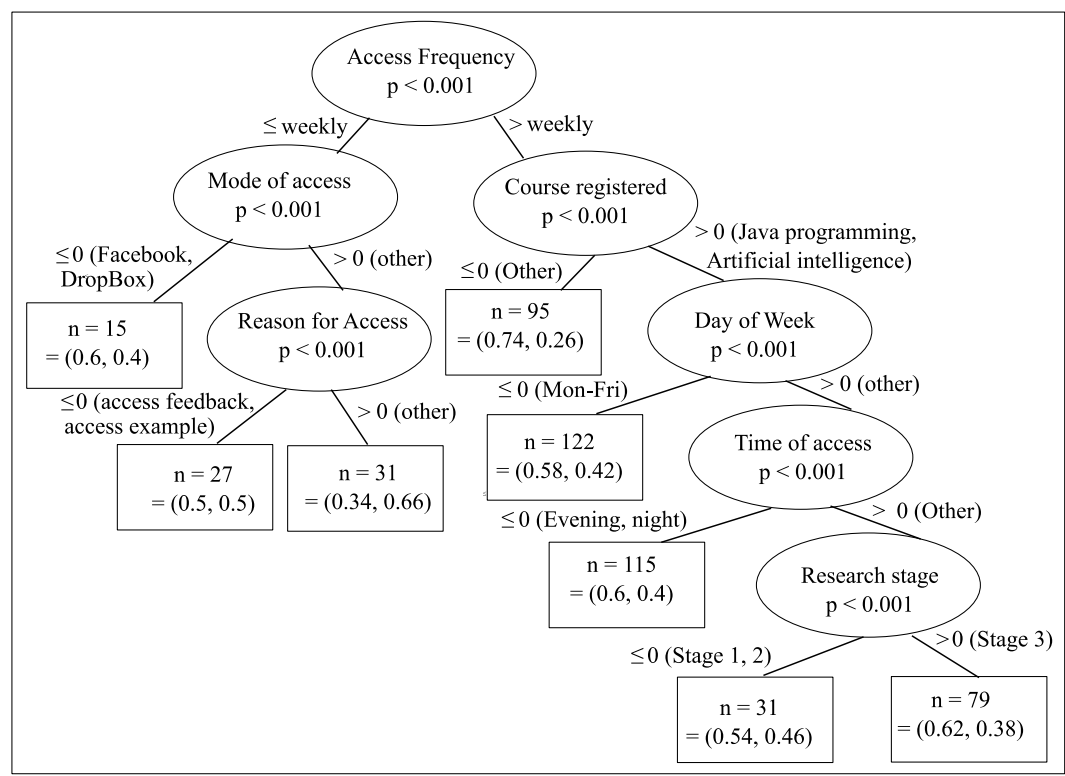

Figure 5. Outcomes from decision tree analysis of different ambient learning variables 


\section{CONCLUSION}

The current research was focused on providing a resource of actionable knowledge through analysis of ambient learning usage statistics to advise improvement of knowledge provision on the cloud. This section offers the theoretical and industrial implications of the study, with its limitations and propositions for future direction.

\subsection{Discussion}

The research has demonstrated integration of the Open Mobile Ambient Learning (OMAL) system with a Knowledge as a Service (KaaS) model for extracting knowledge to advise decision-making processes of ambient learning system developers. The outcomes of this research can help address the issues facing quality and equitable lifelong learning approaches that are not limited by space and time.

Developing countries are increasingly improving their network infrastructures, and private ownership of smart mobile devices. Most learners in developing countries today are being provided with learning resources such as mobile phones, laptops and tablets. This avails a natural platform for ambient learning to thrive. With the convenient internet connection speeds, quality and life-long learning is possible. Additionally, the advanced education systems in developing countries become accessible to all, thus bridging the gap between learners in developed versus developing world.

As demonstrated by Mwendia (2018), the OMAL system provides multi-modal access for ambient learner, but it does not provide opportunities for gathering knowledge from data generated to be able to make changes or decisions. Therefore, this research is a major improvement on the OMAL system architecture since it enables dissemination of knowledge gathered on the knowledge-based system via the proposed cloud service and generates objective actionable knowledge. Such knowledge is more useful for ambient learning experts who can improve the ambient learning system and the general quality of education.

\subsection{Limitations and Future Research Areas}

Results from this study have substantial policy implications, but further work is needed before the procedures can be effective for practical use. First, analysis using a larger sample of data is necessary as the study has used a limited sample. Secondly particular attention should be made to how well the assumptions behind the credibility model are fulfilled and whether improved variables for the model can be found. Thirdly, the current research places focus on the content dissemination. Further research is necessary to evaluate the quality of education, such as by assessing the learning outcomes. A more relevant platform should also showcase how managed cloud services can aid learning.

Finally, future research can extend the current study by comparing results from the methods reported here with those reported among learners in other regions of both developed and developing economies, possibly from the design science methodological perspective. Nevertheless, the work reported in this paper provides valuable insight regarding the dissemination of knowledge to support ambient learning, particularly in areas with limited infrastructures to support conventional learning practices.

\section{REFERENCES}

Al-Busaidi, K.A. 2013. An empirical investigation linking learners' adoption of blended learning to their intention of full e-learning. Behaviour \& Information Technology, Vol. 32, No. 11, pp.1168-1176

Ambient Insight 2013. All Roads Lead Mobile. Accessed from https://ambientinsight.wordpress.com/tag/worldwide/ $(31 / 8 / 2019)$

Asano, Y., Hidaka, S., Hu, Z., Ishihara, Y., Kato, H., Ko, H.S., Nakano, K., Onizuka, M., Sasaki, Y., Shimizu, T. and Tsushima, K., 2018. A View-based Programmable Architecture for Controlling and Integrating Decentralized Data. arXiv preprint arXiv:1803.06674.

Armbrust, M. Joseph A.D and Katz, K. 2009. Above the Clouds: A Berkley View of Cloud Computing. Wiley. New York. de Sousa, L., Kanyimba, A.T. and Bothun, G.D. 2016. Data networks and sustainability education in African universities. International Journal of Sustainability in Higher Education, Vol. 17, No. 2, pp. 246-268. 
General Assembly. 2015. About the Sustainable Development Goals. Accessed from https://www.un.org/sustainabledevelopment/sustainable-development-goals/ (23/8/19)

Grover, V., Chiang, R.H., Liang, T.P. and Zhang, D., 2018. Creating strategic business value from big data analytics: A research framework. Journal of Management Information Systems, 35(2), pp.388-423.

IT News Africa. 2015. Study reveals African mobile phone usage stats. Accessed from https://www.itnewsafrica.com/2015/04/study-reveals-african-mobile-phone-usage-stats/ (23/8/19)

Kaliisa, R. and Picard, M. 2017. A Systematic Review on Mobile Learning in Higher Education: The African Perspective. Turkish Online Journal of Educational Technology-TOJET, Vol. 16, No. 1, pp.1-18.

Kathuria, A., Mann, A., Khuntia, J., Saldanha, T.J. and Kauffman, R.J., 2018. A strategic value appropriation path for cloud computing. Journal of management information systems, 35(3), pp.740-775.

Mwendia, S.N., Wagacha, P.W. and Oboko, R., 2014. Culture Aware M-Learning Classification Framework for African Countries. In Cross-Cultural Online Learning in Higher Education and Corporate Training (pp. 98-111). IGI Global.

Mwendia, S.N., Waiganjo, P. and Oboko, R. 2016). Dynamic Heuristics: Greedy Search: A Mobile Information Retrieval Algorithm for Ambient Learning Systems. In Proceedings of the First African Conference on Human Computer Interaction, pp. 69-79. ACM.

Parsons, D., 2014. The future of mobile learning and implications for education and training. Increasing Access, 217.

Ssekakubo, G., Suleman, H. and Marsden, G. 2013). Designing mobile LMS interfaces: learners' expectations and experiences. Interactive Technology and Smart Education, Vol. 10, No. 2, pp.147-167.

UNESCO. 2015. Kenya National Adult Literacy Survey report. Accessed from https://www.eldis.org/document/A31868 $(23 / 8 / 19)$

Xu, X. 2012. From cloud computing to cloud manufacturing. Robotics and computer-integrated manufacturing, Vol. 28, No. 1 , pp.75-86. 